JINOTEP 5 (2) April (2019): 74-80

JINOTEP (Jurnal Inovasi Teknologi Pembelajaran)

Kajian dan Riset Dalam Teknologi Pembelajaran

http://journal2.um.ac.id/index.php/jinotep/index

\title{
IMPLEMENTASI MODEL PEMBELAJARAN PROBLEM BASED LEARNING (PBL) PADA MATA PELAJARAN PENDIDIKAN PANCASILA DAN KEWARGANEGARAAN (PPKN)
}

Ahyar, Sihkabuden, Yerri Soepriyanto

Teknologi Pendidikan, Universitas Negeri Malang

\section{Article History}

Received: March 21, 2019

Accepted: April 30, 2019

Published: April 30, 2019

\section{Keywords}

\section{PBL}

Proses Pembelejaran Kemampuan Pemacahan Masalah

\begin{abstract}
Abstrak
Penelitian ini bertujuan untuk mendeskripsikan tentang jalanya proses pembelajaran pada mata pelajaran Pendidikan Pancasila dan Kewarganegaraan (PPKn) yang dirancang dengan model pembelajaran Problem Based Learning (PBL) dan dampaknya terhadap kemampuan pebelajar dalam memecahkan masalah. Penelitian ini menggunakan metode deskriptif. Teknik pengumpulan data yang digunakan yakni observasi, wawancara tidak terstruktur, dokumentasi dan tes kemampuan pemecahan masalah. Hasil penelitian menunjukkan bahwa: (1) Implementasi model pembelajaran PBL pada mata pelajaran PPKn di kelas VII F SMPN 13 Malang mampu menciptakan lingkungan belajar kondusif yang ditandai dengan tingginya motivasi dan antuasias pebelajar selama pembelajaran berlangsung. (2) Secara klasikal kemampuan pebelajar kelas VII F SMPN 13 Malang dalam memecahkan masalah setelah mengikuti proses pembelajaran dengan model PBL termasuk dalam kualifikasi Baik.
\end{abstract}

\begin{abstract}
This research aimed to describe the learning process on Civics and Citizenship Education (PPKn) subject using Problem-Based Learning model and its effect on the learner's problem solving skills. The research used descriptive research method. The technique of data collection was observation unstructured interview, documentation, and problem-solving skills test. The research decuded that: (1) The implementation of Problem-Based Learning model on Civics and Citizenship Education (PPKn) subject to learners in VII F class, SMPN 13 Malang, is able to create a conducive learning environment characterized by learners' high motivation and enthusiasm during the learning process. (2) Clasically, the learners' problem solving skill in VII F class, SMPN 13 Malang, after being involved in the learning process using PBL model is qualified as good.
\end{abstract}

Corresponding author :

Ahyar,

Adress: Jalan Semarang No. 5 Malang,

Instansi: Teknologi Pembelajaran Pascasarjana Universitas Negeri Malang

E-mail: ardiantoahyar9@gmail.com
2019 Universitas Negeri Malang p-ISSN 2406-8780 e-ISSN 2654-7953 


\section{PENDAHULUAN}

Salah satu tantangan tersebar yang dihadapi oleh Indonesia saat ini adalah terjadinya degradasi moral bangsa atau dehumanisasi manusia. Kasus-kasus amoral di Indonesia terjadi hampir di semua lini kehidupan. Birokrat, politisi, aparat penegak hukum, akademisi, guru, mahasiswa dan pelajar hingga masyarakat sipil masing-masing memiliki catatan hitam tersendiri dalam hal tindakan tidak terpuji. Kepala daerah dan anggota DPR yang melakukan korupsi, hakim yang terlibat kasus suap, dosen yang terlibat kasus plagiasi, guru yang melakukan pelecehan seksual terhadap muridnya, mahasiswa yang membunuh dosennya, para pelajar yang terlibat pergaulan bebas, tawuran antar pelajar bahkan memukuli gurunya, ayah yang memperkosa dan membunuh anak kandungnya, menjadi berita yang selalu hangat dibicarakan di media massa Indonesia. Semua itu menjadi bukti nyata bahwa bangsa ini sedang krisis moral dan nilainilai karakter.

Pemerintah meyakini bahwa degradasi moral bangsa merupakan ancaman serius yang akan mengganggu keberlangsungan hidup berbangsa dan bernegara. Pemerintah berpandangan bahwa solusi yang paling tepat untuk mengatasi masalah tersebut adalah lewat proses pendidikan. Perlu dilakukan penataan ulang sendi-sendi pendidikan agar lebih mengedepankan pendidikan karakter. Wujud dari hal tersebut yakni dilakukan perubahan kurulum pendidikan dari kurikulum KTSP menjadi Kurikulum 2013 (K 13).

Hal lain yang mendorong terjadinya perubahan kurikulum menjadi $\mathrm{K} 13$ yakni adanya pergeseran paradigma pembelajaran abad 21 yang berpengaruh terhadap model pembelajaran yang akan diimplementasikan dalam pembelajaran. Adapun ciri abad 21 yang berpengaruh terhadap model pembelajaran yakni (1) tersedianya informasi yang dapat diakases kapan saja dan di mana saja, sehingga pembelajaran diorientasikan untuk memacu pebelajar agar aktif menggali bahan pembelajaran dari berbagai rujukan tidak hanya menunggu dikasih tahu, (2) pekerjaan dengan komputasi yang semakin canggih, sehingga pembelajaran diorientasikan agar dapat merumuskan masalah, tidak sekedar mengatasi masalah, (3) tersingkirnya pekerjaan yang prosedural karena adanya automasi sehingga pembelajaran diorientasikan agar mengasah kemampuan berpikir analitis (membuat keputusan) tidak sekedar berpikir mekanis (prosedural), (4) komunikasi yang dapat di berlangsung ke segala arah sehingga pembelajaran lebih mengutamakan kerjasama untuk memecahkan masalah (Litbang Kemdikbud: 2013).

Implikasi dari diberlakukannya kurikulum baru (K 13) secara otomatis akan berdampak pada rancangan proses pembelajaran. Terdapat beberapa model pembelajaran baru yang direkomendasikan oleh pemerintah untuk diimplementasikan pada penerapan kurikulum 2013, salah satunya yakni model pembelajaran Problem Based Learning (PBL).

Model pembelajaran PBL ialah rancangan pembelajaran yang memakai masalah-masalah kongkret dalam kehidupan sehari-hari sebagai sarana agar pebelajar dapat belajar pada taraf berpikir tingkat tinggi. Nurhadi dkk (2004: 56) mengemukakan bahwa model pembelajaran PBL diimplementasikan agar mengasah kemampuan berpikir pada taraf yang tinggi dalam iklim berbasis masalah. Sejalan dengan itu Sanjaya (2008) mendefinisikan bahwa PBL yakni suatu pembelajaran yang mengarahkan pebelajar supaya berpikir tingkat tinggi pada kondisi belajar yang berlandaskan masalah.

PBL mempunyai ciri khusus yang membedakannya dengan model pembelajaran lainnya. Arends (2008) menguraikan lima ciriciri model pembelajaran PBL antara lain (1) pengajuan pertanyaan atau masalah, (2) fokus pada hubungan antar disiplin, (3) penyelidikan otentik, (4) menghasilkan produk atau karya dan memamerkannya, dan (5) kolaborasi. Lebih lanjut Arends (2008) juga menjabarkan tahapan-tahapan dalam mengimplementasikan PBL. Adapun tahapan-tahapannya yakni sebagai berikut. 
76 JINOTEP (Jurnal Inovasi dan Teknologi Pembelajaran) Kajian dan Riset dalam Teknologi Pembelajaran Vol. 5, No. 2, April 2019, Hal. 74-80

Tabel 1 Tahapan-tahapan PBL

\begin{tabular}{ll}
\hline \multicolumn{1}{c}{ Tahap (Fase) } & \multicolumn{1}{c}{ Tindakan Guru } \\
\hline Fase 1: & $\begin{array}{l}\text { Guru menjelaskan tujuan pembelajaran, logistik yang diperlukan, } \\
\text { memotivasi pebelajar supaya terlibat aktif pada aktivitas } \\
\text { memecahkan masalah }\end{array}$ \\
Fase 2: & $\begin{array}{l}\text { Guru menyokong pebelajar mendefinisikan dan } \\
\text { mengorganisasikan tugas belajar yang berkaitan dengan masalah }\end{array}$ \\
Mengorganisasi pebelajar & Guru mendorong pebelajar untuk menghimpun data yang relevan, \\
Fase 3: & mengimplementasikan data yang relevan, melakukan eksperimen, \\
Membimbing penyelidikan individual dan & serta memecahkan masalah \\
kelompok & Guru mengakomodasi pebelajar untuk merancang dan \\
Fase 4: & mengembangkan hasil karya yang relevan seperti laporan, vidoe, \\
Mengembangkan dan menampilkan hasil & dan model serta menolong mereka berbagi tugas dengan rekannya \\
karya & Guru mengakomodasi pebelajar merefleksikan atau mengevaluasi \\
Fase 5: & penyelidikannya dan proses yang dijalaninya \\
Menganalisis dan mengevaluasi proses &
\end{tabular}
pemecahan masalah

Berdasarkan data hasil observasi peneliti

Alasan yang paling mendasar dalam merekomendasikan model pembelajaran PBL ini ialah berdasarkan fakta bahwa setiap individu dalam hidupnya pasti akan menghadapi berbagai permasalahan. Oleh sebab itu setiap individu membutuhkan kemampuan dalam pemecahan masalah. Pebelajar harus dibekali dengan kemampuan pemecahan masalah agar dapat membuat keputusan yang cermat dan tepat. Melalui pembelajaran dengan model PBL ini pebelajar akan terbiasa memecahkan masalah dengan mempertimbangkan berbagai perspektif. Nurhadi dkk (2004) menjelaskan bahwa kemampuan pemecahan dalam pembelajaran dengan model PBL terdiri dari enam aspek yang prosedural yakni kemapuan untuk (1) mengidentifikasi masalah, (2) merumuskan masalah, (3) menganalisis masalah, (4) menarik kesimpulan, (5) melakuakn evaluasi, (6) memecahkan dan menyelesaikan masalah.

Hasil observasi yang dilakukan peneliti menunjukkan bahwa SMPN 13 Malang merupakan salah satu sekolah yang menerapkan K 13 dan model pembelajaran PBL salah satunya diimplementasikan pada mata pelajaran PKn. Ning Sundari, S.Pd selaku guru mata pelajaran tersebut menjelaskan bahwa implementasi model pembelajaran PBL memberikan dampak yang sangat positif pada suasana kelas, pebelajar sangat termotivasi dan antusias untuk mengikuti pembelajaran serta hasil belajar siswa menjadi lebih baik. bertujuan melakukan penelitian untuk mendeskripsikan tentang kondisi kelas saat berlangsungnya proses pembelajaran yang dirancang dengan model PBL (tingkah laku guru dan pebelajar) dan dampaknya terhadap kemampuan pebelajar dalam memecahkan masalah.

\section{METODE}

Penelitian ini menggunakan metode deskriptif. Sugiyono (2011) mengungkapan penelitian deskriptif ialah prosedur ilmiah yang digunakan untuk menjawab masalah secara aktual dengan memaparkan tentang suatu fenomena atau kejadian yang sedang terjadi. Subjek penelitian ini yakni pebelajar kelas VII F SMPN 13 Malang sebanyak 30 orang dan 1 orang guru yang mengampu mata pelajaran PPKn. Pengumpulan data dilakukan melalui observasi, wawancara tidak terstruktur, dokumentasi dan tes kemampuan pemecahan masalah. Analisis data yang digunakan dalam penelitian ini mengacu pada model Miles dan Huberman (1992) yang terdiri dari reduski data, penyajian data, dan verifikasi data. Selanjutnya pengecekaan keabsahan data dilakukan melalui triangulasi

\section{HASIL}

Fokus penelitian ini yakni mendeskripsikan tentang jalannya proses pembelajaran pada mata pelajaran PPKn yang didesain dengan model pembelajaran PBL dan dampaknya terhadap kemampuan pebelajar dalam memecahkan masalah. 


\section{Proses Pembelajaran}

\section{Kegiatan Pendahuluan}

Guru mempersiapkan kelas untuk belajar dan mengajak seluruh pebelajar supaya terlebih dahulu berdoa sesuai agaman dan keyakinan masing-masing. Di awal sebelum masuk ke materi pembelajaran guru mengecek kehadiran pebelajar. Guru selanjutnya memberikan motivasi kepada pebelajar yang dikaitkan dengan materi tentang arti pentingnya persatuan dan kesatuan bangsa. Guru memainkan untuk intonasi bicara untuk meniarik perhatian pebelajar dan langkah terakhir pada kegiatan membuka pembelajaran guru menjelaskan tentang kompetensi dasar dan tujuan yang akan dicapai dalam pembelajaran tersebut.

\section{Kegitan Inti}

Guru mengorientasikan pebelajar untuk fokus pada permasalahan yang akan dipecahkan dengan meminta pebelajar untuk mengamati gambar-gambar yang ditayangkan melalui slide power point terkait permasalahan yang terjadi akibat kurangnya toleransi dalam keberagaman. Guru kemudian membagi pebelajar ke dalam 8 kelompok kecil. Guru menjelaskan bahwa setiap kelompok bertanggung jawab untuk memecahkan satu masalah. Adapun masalah yang diangkat untuk dipecahkan oleh kelompok yakni (1) tawuran antar pelajar, (2) peperangan antar suku di NTT, (3) konflik antar umat beragama, (4) tingginya angka kecelakaan lalu lintas.

Guru kemudian membagikan lembar permasalahan kepada masing-masing kelompok dan guru menuntun kelompok untuk mengidentifikasi masalah yang akan dipecahkan. Setelah kelompok mampu mengidentifikasi masalah, guru langsung membimbing untuk merumuskan masalah ke dalam bentuk pertanyaan. Dalam hal ini guru hanya memberikan contoh secara umum, kelompok tetap bertanggung jawab merumuskan masalah sesuai topik masingmasing.

Dalam rangka membimbing kelompok untuk mengumpulkan data yang relevan dengan masalah, guru menghimbau agar semua kelompok berdiskusi dengan anggotanya. Guru membagikan beberapa surat kabar (koran) untuk kelompok jadikan sebagai sumber data dalam memecahkan masalah. Guru juga menayangkan beberapa berita berbentuk video terkait masalah-masalah yang sedang dipecahkan oleh kelompok. Pebelajar pada masing-masing kelompok tampak sangat antusias dalam berdiskusi, semuanya aktif berpendapat. Pebelajar juga aktif berkonsultasi pada guru saat menemui hambatan. Selama diskusi berlangsung guru melakukan fungsi monitoring. Guru kemudian membimbing kelompok untuk menyimpulkan hasil diskusinya.

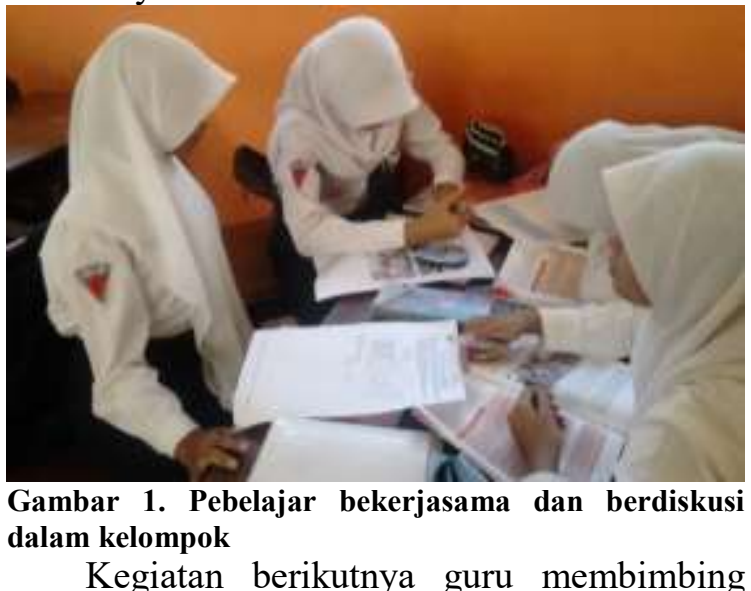
kelompok untuk menyusun laporan sederhana dari hasil diskusi kelompok dalam bentuk pajangan. Pebelajar kembali bekerjasama dalam kelompok untuk membuat pajangan dan kelompok yang sudah selesai diintruksikan oleh guru untuk memajang hasil karyanya di papan tulis. Guru menambahkan bahwa akan diberikan nilai khusus bagi kelompok yang lebih dulu memajang hasil karyanya, sehingga semua kelompok sangat antusias untuk memajang hasil karyanya.

Selanjutnya setiap kelompok diberikan kesempatan untuk menyajikan hasil diskusinya dalam memecahkan masalah. Saat presentasi kelompok pebelajar sangat aktif menyampaikan tanggapan atau bertanya terhadap kelompok penyaji. Sedikit masalah yang terjadi yakni pebelajar kurang menghargai pendapat kelompok lain, sehingga guru perlu mengatasi hal tersebut dengan mengingatkan agar menghargai pendapat temannya.

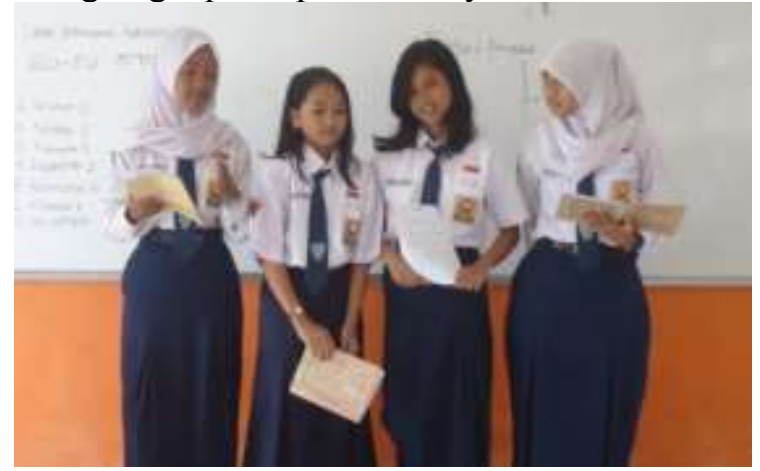


78 JINOTEP (Jurnal Inovasi dan Teknologi Pembelajaran) Kajian dan Riset dalam Teknologi Pembelajaran Vol. 5, No. 2, April 2019, Hal. 74-80

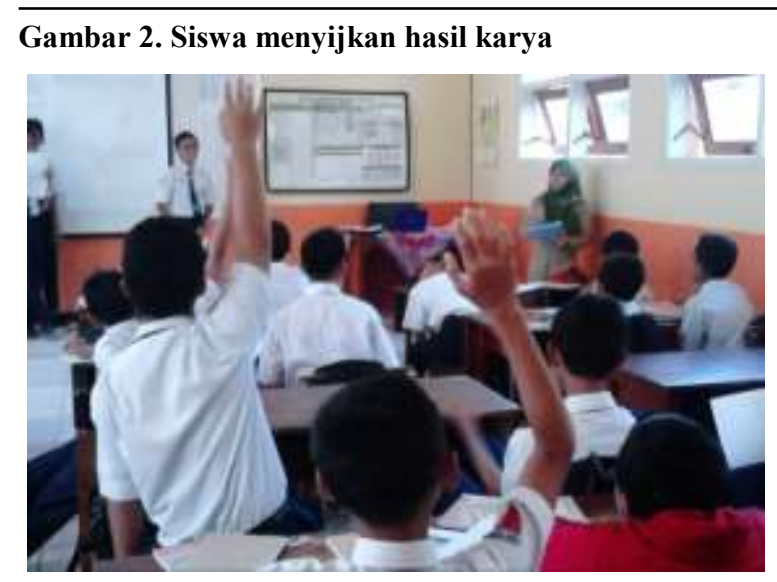

Gambar 3. Keaktifan pebelajar

\section{Kegiatan Penutup}

Hara Guru bersama pebelajar menyimpulkan hasil pembelajaran. Guru guru melakukan refleksi dengan memberi pertanyaan kepada pebelajar terkait manfaat diperoleh setelah belajar tentang materi Bertoleransi dalam Keberagaman. Beberapa pebelajar tampak sangat antusias dalam menjawab.

\section{Kemampuan Pemecahan Masalah}

Dari 34 orang pebelajar yang mengikuti tes kemapuan pemecahan masalah, 8 orang berhasil memperoleh skor 22 dengan nilai 92, 8 orang mendapat skor 21 dengan nilai 88,8 orang memperoleh skor 20 dengan nilai 83,5 orang mendapat skor 19 dengan nilai 79, dan 4 orang memperoleh skro 18 dengan nilai 75 . Maka nilai rata-rata secara klasikal hasil tes kemampuan pemecahan masalah yang diperoleh pebelajar di kelas VII F SMPN 13 Malang yakni 84,9.

\section{PEMBAHASAN}

\section{Proses Pembelajaran}

Merujuk pada data hasil observasi dan wawancara maka dapat dikatakan bahwa guru mata pelajaran PPKn kelas VII F SMPN 13 Malang sudah mengimplementasikan model pembelajaran PBL dengan baik. Guru memiliki pemahaman yang utuh tentang model pembelajaran PBL mulai dari konsep dasarnya, deskripsi tugas guru dan pebelajar selama pembelajaran berlangsung hingga evaluasi.

Arends (2008) merumuskan ada 5 fase atau tahapan yang harus dilakukan ketika mengimplementasikan PBL dalam pembelajaran yaitu (1) orientasi pebelajar pada masalah, (2) mengorganisasi pebelajar untuk belajar, (3) membimbing penyelidikan individual dan kelompok, (4) mengembangkan dan menyajikan hasil karya, (5) menganalisis dan mengevaluasi proses pemecahan masalah. Masing-masing dari fase pembelajaran tersebut sudah dilaksanakan dengan sangat baik oleh guru yang bersangkutan selama pembelajaran berlangsung. Di awal pembelajaran guru menjelaskan tentang 4 jenis permasalahan yang akan dipecahkan, kemudian guru membagi pebelajar dalam beberapa kelompok kecil untuk bekerjama dalam memecahkan masalah. Guru juga membimbing pebelajar untuk mencari informasi yang relevan dengan masalah dari berbagai sumber. Selanjutnya guru membimbing pebelajar untuk menyusun laporan hasil diskusi kelompok dan memberikan kesempatan kepada masingmasing kelompok untuk menyajikan hasil diskusinya dalam memecahkan masalah. Semua kejadian yang diharapkan terjadi pada lembar pemandu observasi tingkah laku guru terlaksana dengan baik selama proses pembelajaran.

Implikasi dari guru yang melaksanakan tugasnya dengan baik tentu berdampak pada suasana kelas. Lalu lintas komunikasi antara pebelajar dan guru, pebelajar dan pebelajar lainnya terjalin dengan baik. Pebelajar tampak sangat aktif dan antusias bekerjasama dalam kelompoknya untuk memecahkan masalah, menyusun laporan, mempresentasikan hasil diskusi kelompok bahkan menanggapi hasil diskusi kelompok lainnya. Data dari hasil wawancara juga terpaparkan bahwa pebelajar senang belajar dengan model pembelajaran PBL karena dapat berkolaborasi dengan temannya. Jadi berdasarkan data hasil observasi tentang fakta-fakta yang terjadi dalam kelas dan data wawancara terkait tanggapan pebelajar terhadap proses pembelajaran, dapat disimpulkan bahwa melalui implementasi model pembelajaran PBL pada mata pelajaran PPKn di kelas VII F SMPN 13 Malang dapat menciptakan lingkungan belajar yang kondusif. 


\section{Kemampuan Pemecahan Masalah}

Penentuan skor (nilai) pebelajar pada tes kemampuan pemecahan masalah dalam penelitian menggunakan rubrik penilaian. Pengembangan rubrik penilaian tersebut mengacu pada enam indikator untuk mengevalusi kemampuan pemecahan masalah pebelajar pada pembelajaran dengan model PBL yang dikemukan oleh Nurhadi dkk (2004: 27). Indkator tersebut antara lain (1) menentukan permasalahan dan menunjukkan femomena yang ada dalam permasalahan, (2) merumuskan masalah dalam bentuk pertanyaan, (3) mengumpulkan data yang relevan dengan masalah, (4) membuat kesimpulan dari masalah yang dianalisis, (5) mengevaluasi berdarkan fakta, prinsip, atau panduan berikutnya menentukan beberapa alternatif solusi, (6) memilih solusi yang tepat untuk menyelesaikan masalah.

Data dari tes kemampuan pemecahan masalah pebelajar kelas VII F SMPN 13 Malang menunjukkan hasil yang positif. Semua skor (nilai) yang pebelajar peroleh di atas SKM (Standar Kompentesi Miminum) yang telah ditetapkan oleh sekolah. Nilai rata-rata klasikal kelas mencapai angka 84, 9 artinya termasuk dalam kategori sangat baik. Jadi berdasarkan data hasil tes kemampuan pemecahan masalah ini dapat diketahui bahwa implementasi model pembelajaran PBL pada mata pelajaran PPKn dapat memberikan dampak positif dalam mengasah kemampuan pebelajar dalam pemecahan masalah.

Penelitian tersebut sejalan dengan hasil penelitian Prayogi (2017) yang menyimpulkan hasil yang sama pada mata pelajaran $\mathrm{K} 3$ di SMK. Senada dengan hasil penelitian Nurhidayati (2018) yang menyebutkan bahwa model PBl dapat meningkatkan hasil belajar siswa. Wayuningati (2017) juga dengan kesimpulan yang sama bahwa PBL meningkatkan hasil belajar. Penelitian lainnya dari Suyetno (2017) yang menyatakan bahwa PBL dapat meningkatkan hasil belajar siswa pada Mata Pelajatan Teknik Kerja Bengkel. Berdasarkan hasil temuan dari penelitian di atas dan beberapa penelitian yang mendukung hasil temuan dapat ditarik simpulan bahwa PBL terbukti efektif dalam membantu proses peningkatan hasil belajar siswa

\section{SIMPULAN}

Berdasarkan data hasil penelitian yang telah dilaksanakan maka dapat disimpulkan bahwa implementasi model pembelajaran PBL pada mata pelajaran PPKn di kelas VII F SMPN 13 Malang mampu menciptakan kelas atau lingkungan belajar yang kondusif. Hal ini karena guru mampu melaksanakan tugasnya dengan baik dalam mengimplementasikan setiap fase-fase pembelajaran dalam model PBL sehingga pebelajar menjadi termotivasi dan antusias dalam mengikuti pembelajaran.

$$
\text { Melalui implementasi model }
$$
pembelajaran PBL pada mata pelajaran PPKn di kelas VII F SMPN 13 Malang dapat memberikan dampak yang positif dalam mengasah kemampuan pebelajar untuk memecahkan masalah.

\section{DAFTAR RUJUKAN}

Arends, R.I. (2008). Learning to Teach Six Edition. Yogyakarta Pustaka Belajar.

Litbang Kemdikbud. (2013) Kurikulum 2013 Pergeseran Paradigma Abad 21. Retrieved April 1, 2019, from website: http://litbang.kemdikbud.go.id.index.php/inde x-berita-kurikulum/243-kurikulum-2013pergerseran-paradigma-belajar-abad-21

Miles, M.B., Huberman, A.M. (2009). Analisis Data Kualitatif. Bandung: PT Remaja Rosdakary

Nurhadi, B. Y., \& Senduk, A. G. (2004). Pembelajaran kontekstual dan penerapannya dalam KBK. Malang: Universitas Negeri Malang Pres.

Prayogi, D., Sudjimat, D. A., \& Mariana, R. R. (2019). Pengembangan bahan ajar K3 dan higiene sanitasi berbasis PBL untuk meningkatkan hasil belajar siswa SMK. Teknologi dan Kejuruan: Jurnal Teknologi, Kejuruan, dan Pengajarannya, 40(1), 7986.

Nurhidayati, A., Putro, S. C., \& Widiyaningtyas, T. (2018). Penerapan model PBL berbantuan e-modul berbasis flipbook dibandingkan berbantuan bahan ajar cetak pengaruhnya terhadap hasil belajar pemrograman siswa SMK. Teknologi dan Kejuruan: Jurnal Teknologi, Kejuruan, dan Pengajarannya, 41(2), 130-138.

Sanjaya, W. (2008) Strategi Pembelajaran Berorientasi Standar proses Pendidikan. Jakarta: Kencana.

Sugiyono. (2011). Metode Penelitian Kualitatif. Bandung: Rosdakarya. 
80 JINOTEP (Jurnal Inovasi dan Teknologi Pembelajaran) Kajian dan Riset dalam Teknologi Pembelajaran Vol. 5, No. 2, April 2019, Hal. 74-80

Suyetno, A., Irniyah, E., Elmunsyah, H., \& Hoggowiyono, P. (2017). Penerapan model PBL pada mata pelajaran teknik kerja bengkel untuk meningkatkan motivasi, aktivitas dan hasil belajar siswa dI SMK. Teknologi dan Kejuruan: Jurnal Teknologi, Kejuruan, dan Pengajarannya, 40(1), 1320.
Wayuningati, N. R. (2017). Penerapan problem based learning dan media flipcart untuk meningkatkan hasil belajar ipa materi ekosistem siswa. Ilmu Pendidikan: Jurnal Kajian Teori dan Praktik Kependidikan, 2(2), 184-188. 